Session 1526

\title{
Real Chemical Reactions Vertically Integrated Throughout the Curriculum
}

\author{
Robert P. Hesketh, Kevin Dahm, Stephanie Farrell, Mariano Savelski and \\ C. Stewart Slater in Chemical Engineering, and Robert Newland in Chemistry \\ Rowan University
}

\begin{abstract}
At Rowan we are putting into practice an emphasis on hands-on experiments throughout the curriculum. We are attempting to employ an inductive learning style, in which students first conduct an experiment and visualize relationships; then they learn the related theory; and finally they design experiments in the engineering clinics.

The pedagogy of teaching chemical reaction engineering is continually advancing through the use of new computational tools such as POLYMATH and MATLAB; interactive computer applications; and a new emphasis in textbooks on relating theory to industrially relevant chemical reactions. What is currently lacking in this area are chemical reaction engineering experiments that employ realistic reaction engineering systems. Nearly all of the reaction engineering experiments, reported in the literature, employ simple experiments that can be described using a single overall reaction. In addition most laboratory experiments do not examine the process fluid mechanics of the reactor and how this effects the product distribution. As a result, students only visualize reactors through theory and do not experience realistic reactor systems in their undergraduate courses. This lack of experience eliminates a major engineering challenge in designing and troubleshooting a reactor in which the yield and selectivity are optimized along with the process economics.

In this proposal we will develop several experiments that employ the following features that are currently not being addressed in published reaction engineering experiments: 1) byproduct formation, 2) green engineering, 3) scale-up fluid mechanics and 4) equilibrium limited reactions. We will adapt a series of experiments from the research and educational literature using 3 chemical and 1 biological reacting systems. These experiments will be vertically integrated through the following series of courses: chemistry, organic chemistry, and process fluid transport, chemical reaction engineering, industrial process pathways, biochemical engineering, and unit operations. We believe that these realistic reactor experiments will produce students with a clear understanding of the fundamental issues in reaction engineering.
\end{abstract}

\section{Project Description}

Reaction engineering is one of the cornerstones of chemical engineering education. In a recent report titled, "Technology Vision 2020: The U.S. Chemical Industry ", chemical synthesis was recognized as one of the three primary areas within the chemical sciences that requires long term

"Proceedings of the 2002 American Society for Engineering Education Annual Conference \& Exposition Copy- 1 right (C) 2002, American Society for Engineering Education" 
investment in research and development. A second area identified in the Vision 2020 report was in enabling technologies such as process science and engineering technology. Both of these areas are covered under the broad term of chemical reaction engineering. One of the major shortcomings of current chemical reaction engineering pedagogy is a lack of focus on real reactors and reaction systems. Most laboratory experiments in reaction engineering are designed to be described by a single overall reaction and reactions that form byproducts are avoided. In industrial reactors unwanted byproduct formation is a serious problem. In addition, considering byproduct formation presents the engineer with an opportunity to employ the field of green chemistry. With the advent of easy to use analytical instrumentation we believe that experiments in reaction engineering should now progress to examining systems with multiple reaction products. In this manner we will integrate new technology into reaction engineering experiments.

\section{Goals and Objectives}

The goal of this project is to create reaction engineering experiments that are similar to industrial reactors in that they contain multiple chemical reactions. The instructional objectives for students completing these laboratories are listed below. Students after completing the proposed reaction engineering experiments should be able to:

1) Understand the development process from basic process chemistry to pilot plant reactors

2) Design a series of pilot scale experiments to determine the maximum selectivity for a desired chemical based previous experiments performed in organic chemistry and reaction engineering courses.

3) Determine the chemical pathways for a given reaction system, based on data obtained in class and from data obtained from students in related classes of organic chemistry, reaction engineering and unit operations.

4) Evaluate a chemical mechanism based on experimental data.

5) Critique the applicability of experimental results obtained from lab, bench and pilot plant equipment for use in simulating commercial systems with multiple reactions.

6) Experimentally investigate two methods of ethanol production and compare their process economics, safety, and social and environmental issues.

7) Determine the optimum agitation speed and location of the feed outlet for a liquid phase competitive-consecutive reaction system.

8) Explain the differences between the simulation results of a perfectly mixed reactor and the experimental results obtained using a 20 gallon reactor with a 6 inch Rushton tubine and one baffle for a multiple reaction system.

9) Design a chemical process that can achieve a higher conversion than that predicted by equilibrium calculations of a single ideal batch, continuous stirred tank or tubular reactor.

"Proceedings of the 2002 American Society for Engineering Education Annual Conference \& Exposition Copyright (C) 2002, American Society for Engineering Education" 


\section{Current Practice}

Much work has been done in the pedagogy of teaching reaction engineering. There are several excellent reaction engineering textbooks and in the past 5 years extensive use of numerical methods from easy to use packages such as POLYMATH and Matlab. Interactive computer software modules are also being developed which enable the student to increase their understanding of chemical reaction engineering.

Textbooks in reaction engineering have progressed from a simplified treatment of chemical reactions to presenting more realistic process chemistry and reaction mechanisms. In traditional reaction engineering textbooks, reactions are represented using generic, symbolic notation such as: $A+B \Leftrightarrow C+D$. This is a good tool to introduce reaction engineering to students, but has been deemed by the engineering profession to lack a relationship to reality. Many of the current chemical reaction engineering texts have incorporated numerous examples and problems using realistic chemistry such as the texts by Fogler ${ }^{2}$ and Schmidt ${ }^{3}$. In addition, the use of numerical methods in easy to use packages such as POLYMATH and MATLAB has enabled chapters in multiple reactions to use more complex reaction mechanisms beyond those of the classic parallel $\mathrm{A}+\mathrm{B} \rightarrow \mathrm{D}$ and $\mathrm{A}+\mathrm{B} \rightarrow \mathrm{U}$ and series $\mathrm{A} \rightarrow \mathrm{B} \rightarrow \mathrm{C}$ models.

The current state-of-art in reaction engineering experiments has focused on experiments that can be described using a single overall reaction such as the liquid phase saponification reaction, $\mathrm{NaOH}+\mathrm{C}_{2} \mathrm{H}_{5} \mathrm{CO}_{2} \mathrm{CH}_{3} \Leftrightarrow \mathrm{C}_{2} \mathrm{H}_{5} \mathrm{OH}+\mathrm{C}_{2} \mathrm{H}_{5} \mathrm{COONa}$ which is employed by the equipment manufacturers of Armfield and Perfected Instruments and many other universities such as NJIT. In the gas phase either a combustion reaction is employed as in the heterogenous combustion of carbon rods conducted at the University of Illinois or a catalytic oxidation experiment developed by Abraham or Hesketh ${ }^{4}$. The commonality in all of these reaction experiments is that they can be effectively described by a one step reaction mechanism. In addition, many of these reactions can be modeled as first order, since one of the reactants is in excess.

In many industrial reactors there are several products that are formed and these need to be optimized. For example, maleic anhydride can be formed from the partial oxidation of butane, but other byproducts such as $\mathrm{CO}, \mathrm{CO}_{2}$ or miscellaneous hydrocarbons are also formed. Using current mathematical packages such as POLYMATH or MATLAB, these multiple reaction systems can be modeled and examples and homework problems for these reaction systems are given in the textbooks for the course. Unfortunately there are no experiments that have been prepared for undergraduates to demonstrate basic reaction engineering principles associated with multiple reactions. With the current availability of advanced analytical instrumentation in most chemical engineering departments and the relative easy of use of these instruments through windows style software, multiple product experiments should now be created.

A second issue lacking in teaching reactor design to undergraduates is in mixing and reactions. In the chapter on multiple reactions it is assumed that the reactions are slow compared to the mixing of species. The classic examples for parallel reactions and series reactions are given, but these examples do not cover the basic concept of micro-mixing with respect to the reactants. Only in the final chapter of Fogler's text ${ }^{2}$ is the concept of micro-mixing introduced using a relatively complex mathematical theory for undergraduates. We believe that a series of experiments 
varying in scale from the size of a coffee cup to a 20 gallon reactor will demonstrate realistic reaction engineering problems encountered in industry. These experiments will give the basic problems associated with this phenomenon and encourage the student to further their studies in this area.

A third issue that is slowly being addressed in textbooks and laboratory experiments is to expand the application of reaction engineering to non-traditional chemical engineering fields. There are numerous bioengineering experiments that have been developed, but these are specifically developed for a bioengineering course. In this proposal we will be adapting several bioengineering experiments to be used within a series of courses including chemical reaction engineering, bioengineering and process chemical pathways.

The fourth issue that will be addressed in this proposal is the vertical integration of experiments starting in chemistry and biology and continuing through advanced chemical engineering courses. In many cases experiments are introduced in the Organic Chemistry Laboratory and then are never addressed again. This philosophy propagates a student perception that basic chemistry is not very important to their careers. To counter this perception, we will link organic chemistry with reaction engineering and chemical process pathways courses through a series of common experiments. This will illustrate to the student the importance of using chemistry fundamentals to design chemical reactors.

\section{Reaction Engineering Experiments}

We are proposing to develop and implement a set of 4 experiments. Each of these experiments will be integrated through various levels in the curriculum.

\section{Micro-Mixing Experiment}

In practice the issue of mixing and chemical reactions is economically very important in chemical reaction engineering. A major issue in industrial reactors is to optimize the desired products. This optimization is a function of reactor geometry, the chemical and physical characteristics of the reacting system, the degree of mixing and the mode of supplying the reactor with reagents.

Bourne and Gablinger ${ }^{5}$ have shown how process chemistry developed in the laboratory can go awry when scaled to industrial reactors. An excellent example of the classic series-parallel reaction using an azo dye chemistry is presented by Bourne and Gholap. ${ }^{6}$ The chemist will optimize the reaction to obtain very high reaction rates for the desired reaction. However, in the industrial reactor, micromixing occurs, negatively impacting the process chemistry. ${ }^{7}$ However, as explained by Etchells ${ }^{8}$ (1998), a typical undergraduate reactor design course focuses on ideal reactors and would overlook the impacts of mixing on the reaction chemistry and the formation of trace byproducts. This problem is very significant in polymerization reactions in industry.

Baldyga and Bourne ${ }^{9}$ summarize a number of experimental examples of product distributions sensitive to mixing that will be investigated in this proposal. Examples of parallel or competitive reactions include Diazo coupling with simultaneous reagent decomposition ${ }^{10}$ and Iodate/iodine 
reaction with neutralization. ${ }^{11}$ Examples of parallel - series reactions or competitive-consecutive reactions include Diamines with isocyantes or other acylating agents, nitrations of dibenzyl, durene, and alkyl benzenes and diazo couplings.

Baldyga and Bourne ${ }^{9}$ recommend several chemical systems for model verification of chemically reacting flows. We believe that these model systems can be adapted for undergraduate chemical reaction engineering laboratories. Two experiments will be investigated for possible use in student laboratories: (1) competitive neutralization of HCL and alkaline hydrolysis of monochloroacetate esters with $\mathrm{NaOH}$. (2) diazo coupling of 1-naphthol and diazotized sulphanilic acid. ${ }^{12,13}$ Both of these systems satisfy the requirements for turbulent reacting flows model validations of fast reactions relative to mixing, accurate quantitative analysis, known kinetics, safe and relatively inexpensive reagents, and the use of water as the solvent. We will require the same conditions in our undergraduate level experiments.

For these experiments we will use a competitive neutralization and hydrolysis system with the following chemistry:

$$
\begin{aligned}
& \mathrm{HCl}+\mathrm{NaOH} \stackrel{k_{1}}{\longrightarrow} \mathrm{H}_{2} \mathrm{O}+\mathrm{NaCl} \\
& \mathrm{NaOH}+\mathrm{C}_{2} \mathrm{H}_{5} \mathrm{CO}_{2} \mathrm{CClH}_{2} \stackrel{k_{2}}{\longrightarrow} \mathrm{C}_{2} \mathrm{H}_{5} \mathrm{OH}+\mathrm{CClH}_{2} \mathrm{COONa}
\end{aligned}
$$

with sodium hydroxide as the limiting reagent. This reaction is fast compared to the rate of mixing and reaction 1 is faster than then reaction 2 . With this chemistry at high stirrer speeds the reaction network will be controlled by the reaction kinetics and almost no acetate and alcohol will be formed. At low stirrer speeds the $\mathrm{NaOH}$ will react with both the acid and the ester and a yield of ester of 0.5 is expected. The students will perform the following experiments:

1. Effect of stirrer speed on product distribution - Batch

2. Effect of placement of feed tube location - Batch

3. CSTR with continuous addition of reagents and removal of products.

The above 3 experiments will be repeated using the pilot plant reactor ( 20 gallon). Using this reactor it will be demonstrated that the same energy per unit mass input can not be achieved in the large unit as in the small unit. This experiment will clearly demonstrate the problems of scale-up of chemical reactions from bench to pilot to full-scale production.

It is expected that the first experiment would be conducted in the chemical reaction engineering class; experiment 2 and 3 in the process fluid transport course and a fourth experiment would be designed by students for the unit operations laboratory.

\section{Bioreaction Engineering Experiment}

The objectives of the proposed experiments are to: (1) investigate enzyme kinetics, (2) to compare the performance of immobilized enzymes and cells to that of their free counterparts in batch bioreactors and (3) to investigate the performance of two continuous bioreactors (4) examine the 
product distribution obtained from these reactors. Students will collect and analyze kinetic data, obtain values of intrinsic and observed kinetic parameters, and evaluate the performance of immobilized enzymes and cells using criteria established for heterogeneous catalyst systems (effectiveness factors).

Several universities have introduced biochemical engineering courses and laboratories into their chemical engineering curricula, primarily at the senior level as elective courses. Nam Sun Wang at the University of Maryland has developed an extensive biochemical engineering laboratory, and has introduced several experiments that explore in depth free and immobilized enzyme kinetics, as well as a continuous bioreactor. The experiments we plan to implement at Rowan have been adapted from those described by Dr. Wang ${ }^{14}$

\section{1) Substrate conversion using free and immobilized enzymes}

In this experiment students explore the kinetics of the enzymatic degradation of potato starch as it is broken down into sugars such as dextrin, maltoriose and maltose. The experiment involves a simple batch reactor and alpha-amylase enzyme. The distribution of sugars will be measured using HPLC. The effects of parameters such as temperature and substrate concentration on enzyme activity and ultimate conversion to maltose will be investigated. For the immobilized enzyme experiments, the enzyme will be entrapped within a calcium alginate bead. The size of the bead, which is determined by the needle gauge, is important because internal mass transfer limitations can prevent the substrate from penetrating deep into the bead, resulting in an inactive core region. The immobilized enzyme experiment will have a further objective of determining an effectiveness factor.

\section{2) Substrate conversion using immobilized cells}

As with enzyme immobilization, whole cell immobilization permits the recovery and re-use of cells from bioreactors. Again, mass transfer limitations are often significant in gel-entrapped cell systems, and oxygen limitations are often most severe due to the low solubility of oxygen in the aqueous phase surrounding the beads. This can be an important concern with aerobic reactions. In this experiment, students investigate the use of free and immobilized cells in batch and fedbatch bioreactors. Saccharomyces cerevisiae is a robust yeast that anaerobically converts glucose to ethanol with acetaldehyde as an intermediate. The yeast, however, are also capable of aerobic respiration which produces carbon dioxide as an end product, and organic acids as intermediates. Both free cells and cells entrapped in alginate beads will be used. Students will monitor the substrate and product concentrations, as well as the free cell concentration in the bioreactor. The apparent reaction kinetics will be compared with the intrinsic kinetics of free cells in a continuous bioreactor. They will investigate the effect of oxygen concentration and $\mathrm{pH}$ on intermediate and by-product formation.

\section{3) Packed bed and fluidized bed immobilized enzyme bioreactors}

Continuous bioreactors offer several advantages over their batch counterparts. Automation and control lead to lower cost and more consistent product quality. As mentioned previously, enzyme immobilization can be used in continuous bioreactors to retain the enzyme within the bioreactor. In this experiment, students will study the conversion of starch to sugar in a continuous 
imm7obilized enzyme bioreactor. Two reactor configurations will be studied: a packed bed and a fluidized bed. Students will investigate the effect of external mass transfer resistance by varying the flowrate through the column. They will determine the effect of flow rate on conversion, and they will compare the apparent kinetic constant with the intrinsic kinetic constant.

\section{Ethyl Acetate Production: Reactive Distillation}

The final series of experiments will be based on a second equilibrium limited reaction; the production of ethyl acetate. Students will first perform this esterification experiment in Organic Chemistry using a total reflux apparatus with a volume of $0.1 \mathrm{~L}^{15}$. Next, students will perform this experiment in reaction engineering using a small-scale distillation apparatus having a volume of $0.5 \mathrm{~L}$. This experiment will be adapted from the procedures given by Keyes ${ }^{16}$ and descriptions of a similar Eastman Chemical Company process. ${ }^{17}$ By comparing the results of the total reflux experiment with those of the fractionation experiment students will see how a reaction can be engineered to achieve higher conversions of products. Finally in Unit Operations the esterification experiment will be performed in our 20 gallon glass lined reactor which is part of our pilot plant facility. In these experiments students will utilize information gained in the lab and bench scale to set parameters for this combined reaction and separation experiment. Using this series of experiments, chemical engineers and chemists will see the development of a process from laboratory experiments to a pilot plant scale.

\section{Implementation of Project}

The project will require 3 years of funding because of the time required to plan, develop and implement the pilot scale experiments and the need to assess one set of students through both the vertically integrated and consecutive set of experiments. The students will take the sequence of courses and experiments shown in the table below.

\begin{tabular}{|l|l|l|}
\hline Semester & Course & Experiments \\
\hline Spring 2002 & Organic Chemistry & Esterification and alcohol production \\
\hline Fall 2002 & Process Fluid Transport & $\begin{array}{l}\text { Mixing Experiments with test reaction system - effect of stir- } \\
\text { rer speeds }\end{array}$ \\
\hline Spring 2003 & Chemical Reaction Engineering & $\begin{array}{l}\text { All experiments except pilot plant and previous mixing ex- } \\
\text { periment }\end{array}$ \\
\hline Fall 2003 & Biochemical Engineering & Biochemical production of alcohol and sugars \\
\hline Spring 2004 & Industrial Process Pathways & $\begin{array}{l}\text { A sampling of experiments and additional data from the Jun- } \\
\text { ior and Sophomore Semesters. } \\
\text { Pilot Plant Experiments }\end{array}$ \\
\hline
\end{tabular}

To optimize the time that students spend performing experiments and the quality of results, experimental data from previous courses will be collected and given to all students. Using this procedure, all students will be familiar with the equipment, but will not have to conduct repeti-

"Proceedings of the 2002 American Society for Engineering Education Annual Conference \& Exposition Copy- 
tive trials. In addition, Senior students will have the opportunity to re-examine a process, such as ethanol or ester production which they have seen in a prior course from a new perspective and from a position of greater knowledge. The senior will use the data from the lower level courses to design experiments for the pilot plant equipment. This synthesis of the data from these different perspectives and scales of equipment will prepare the student for the types of problems they will be required to solve in industry.

\section{Conclusions:}

In this proposal we are developing several experiments that employ the following features that are currently not being addressed in published reaction engineering experiments: 1) byproduct formation, 2) green engineering, 3) scale-up fluid mechanics and 4) equilibrium limited reactions. These experiments are being adapted from the research and educational literature using 3 chemical and 1 biological reacting systems. These experiments will be vertically integrated through the following series of courses: chemistry, organic chemistry, and process fluid transport, chemical reaction engineering, industrial process pathways, biochemical engineering, and unit operations. We believe that these realistic reactor experiments will produce students with a clear understanding of the fundamental issues in reaction engineering.

\section{Acknowledgements}

Support for the laboratory development activity described in this paper is provided for by a grant (DUE- 0088501) from the National Science Foundation through the Division for Undergraduate Education.

\section{BIBLIOGRAPHIC INFORMATION}

${ }^{1}$ American Chemical Society, American Institute of Chemical Engineers, The Chemical Manufacturers Association, The Council for Chemical Research, The Synthetic Organic Chemical Manfacturers Manufacturers Association, Technology Vision 2020, American Chemical Society, Washington DC, 1996

${ }^{2}$ Fogler, H. Scott, Elements of Chemical Reaction Engineering, $3^{\text {rd }}$ Ed., Prentice Hall PTR, New Jersey 1999.

3 Schmidt, L. D., The Engineeering of Chemical Reactions, Oxford University Press, New York, (list of chemical reactions on page 9) 1998.

Hesketh, R. P. and D. Bosak and L. Kline, “Automotive Catalytic Reaction Engineering Experiment," Accepted for Publication in Chem. Eng. Educ., October 1999.

5

Bourne, J.R.; Gablinger, H., "Local pH gradients and the selectivity of fast reactions. II. Comparisons between model and experiments." Chemical Engineering Science 44 (6) p 1347-1352 (1989).

6

Bourne, J.R.; Gholap, R.V, "Approximate method for predicting the product distribution of fast reactions in stirred-tank reactors," Chemical Engineering Journal and Biochemical Engineering Journal 59(3) 293-296 (1995)

7

Baldyga, J.; Bourne, J.R.; Hearn, S.J., "Interaction between chemical reactions and mixing on various scales," Chemical Engineering Science 52 (4) p 457-466 (1997).

"Proceedings of the 2002 American Society for Engineering Education Annual Conference \& Exposition Copy- 8 right (C) 2002, American Society for Engineering Education" 
8

Etchells, A., Notes on Mixing in the Process Industries, lecture and short course material, DuPont USA, Wilmington, DE., 1998.

${ }^{9}$ Baldyga, J. and J. R. Bourne, Turbulent Mixing and Chemical Reactions, John Wiley \& Sons, Chichester, 1999. 10 Nienow A. W., S. M. Drain, A. P. Boyes, R. Mann, A. M. El-Hamouz and K. J. Carpenter "A new pair of reactions to characterise imperfect macromixing and partial segregation in a stirred semi-batch reactor," Chem Eng Sci 47 2825-2830 (1992).

${ }^{11}$ Fournier, M. C., L. Flak, and J., Villermaux “Anew parallel competing reaction system for assessing micromixing efficiency: experimental approach” Chem. Eng. Sci. 51, 5053-5064 (1996). Also given in AIChE Symp Ser 88 (1992) No. 286 and 90 (1994) No. 299

12 Bourne, J. R., O. M. Kut, J. Lenzner, and H. Maire, "Kinetics of the diazo coupling between 1-naphthol and diazotized sulfanilic acid," Ind. Eng. Chem. Res. 29 1761-1765 (1990).

${ }^{13}$ Bourne, J. R., E. Crivelli and P. Rys, “Mixing disguised azo coupling reactions,” Helv. Chim. Acta 60 2944-2957 (1977).

${ }^{14}$ Wang, Nam Sun, Course Website for Biochemical Engineering Laboratory at University of Maryland, Spring 2000, http://www.glue.umd.edu/ nsw/ench485/ench485.htm

15

Nimitz, J. S. Experiments in Organic Chemistry: From Microscale to Macroscale, Prentice Hall 1991.

16

Keyes, D. B., "Esterification Processes and Equipment," Industrial and Engineering Chemistry 24 (10) 1096 (1932).

${ }^{17}$ Doherty, M. F., and G. Buzad, “Reactive Distillation by Design,” Trans IChemE, 70 Part A 448 (1992)

\section{BIOGRAPHICAL INFORMATION}

Robert Hesketh is a highly motivated professor in both undergraduate and graduate education and has received 9 education and 2 research awards, including ASEE's 1999 Ray W. Fahien Award. He has made major contributions in laboratory methods that demonstrate chemical engineering practice and principles. These highly visual and effective experiments, the most notable using the vehicle of a coffeemaker, are used to introduce engineering design and science to university and pre-college students. He has developed over 17 experiments employed throughout the curriculum at Rowan University. These experiments range from small scale coffee experiments to $25 \mathrm{ft}$ distillation column experiments. Of special interest to this proposal, Dr. Hesketh has designed and fabricated several reaction apparatus including: fluidized bed apparatus ${ }^{18}{ }^{19},{ }^{20}$, gas-phase flow reactors ${ }^{21}, 22$, and a catalytic reactor . Dr. Hesketh has also conducted work on biological and chemical gas-liquid reactors, and batch and continuous stirred tank reactors. Dr. Hesketh has taught undergraduate and graduate level chemical reaction engineering since 1990. His work has been presented at national meetings, workshops and published in journals and proceedings and his experiments are being used in over 15 institutions. He has attracted over 1 million dollars in external funding for research and educational activities.

Robert is highly active in both ASEE and AIChE. He has undertaken leadership roles in engineering practice and professional service through chairing a topical conference on Engineering Education at the AIChE 2000 Annual Meeting, chairing 10 technical and education sessions at national meetings. He is the Chair of Group 4a: Undergraduate Education in AIChE and Membership Chair of ASEE's chemical engineering division.

"Proceedings of the 2002 American Society for Engineering Education Annual Conference \& Exposition Copyright (C) 2002, American Society for Engineering Education" 
Kevin Dahm is an Assistant Professor in his first year with the Department of Chemical Engineering. He has extensive experience in the area of kinetics having completed his disseration in chemical engineering at MIT in the area of kinetic modeling of hydrocarbon pyrolysis. As a postdoctoral researcher at UCBerkeley he developed innovative process simulation software. Before coming to Rowan he taught Chemical Reaction Engineering and Chemical Engineering Thermodynamics as an adjunct professor at North Carolina A\&T State University. With Rowan, he has taught Industrial Process Pathways, Sophomore Engineering Clinic, and Mass Transfer, and has supervised undergraduate research projects on hydrocarbon pyrolysis, combustion of propane in a fluidized bed and ethane dehydrogenation by catalytic membrane reactors.

Stephanie Farrell is an Associate Professor of Chemical Engineering at Rowan and her positive impact on education will be recognized with the 2000 ASEE-Dow Outstanding Faculty Award. She has generated novel pedagogical techniques and numerous exciting laboratory experiments and new courses for freshman through graduate level, and she has published and presented extensively in these areas. She has integrated bio-related topics and experiments throughout the $\mathrm{ChE}$ curriculum, from freshman to graduate level. In this project she will be responsible for the development and set-up of the enzyme and whole cell experiments.

Mariano J. Savelski is an Assistant professor in his first year with the Department of Chemical Engineering. His dissertation the University of Oklahoma was in the area of green engineering through process design and optimization with special emphasis in industrial wastewater reuse. He has seven years of industrial experience at Kellogg's in the design and technology area. At the University of Oklahoma, he has taught Unit Operations Lab and Chemical Engineering Design both for two semesters. He has also helped develop virtual experiments in fluid mechanics, his contribution was in the field of boundary layer simulation. At Rowan, he has set up the Unit Operations Lab and developed the Student and Safety Manuals for the course. He has taught Unit Operations Lab, Chemical Process Component Design and Chemical Plant Design, and supervised an industrial-sponsored undergraduate research project.

C. Stewart Slater has been recognized nationally by several awards, based on his excellence as an innovative educator: George Westinghouse Award (ASEE), John Fluke Award (ASEE), and Dow Outstanding Faculty Award (ASEE). Dr. Slater has over 60 publications and 50 presentations at professional society meetings. Much of his research is industrially applied and he has translated these concepts to undergraduate teaching. As a teacher, Dr. Slater has done extensive work on curriculum and has received grants to establish new laboratories and enhance existing ones, published extensively in laboratory and curriculum development, created new courses and methods, and serves as an invited lecturer to other institutions and industry. His educational philosophy involves hands-on instruction using the latest technological advances. While at Manhattan College he received three NSF ILI-IP grants in the areas of advanced separation process laboratory development. Dr. Slater has expertise in biotechnology and biochemical engineering as evidenced by his fourth NSF-ILI grant.

Robert Newland has been a Professor in the Department of Chemistry and Physics for 17 years and Chair of the department for eight years. He has extensive expertise in the field of organic chemistry, having served as an instructor in Organic Chemistry for Rowan as well as Lafayette and Illinois, as well as publishing research in the area. He has also played a significant role in working with the College of Engineering by developing a 1-semester organic chemistry course for engineers and chemists and developing a new Advanced College Chemistry sequence taken by all engineering students.

\footnotetext{
${ }^{18}$ Hesketh, R. P., and J. F. Davidson, "Combustion of methane and propane in an incipiently fluidized bed." Combustion and Flame 85449 (1991).

19

Raffensperger, C., R. A. Pendergrass, and R. P. Hesketh, "The Inhibition of Propane Combustion within a Fluidized Bed" Paper No. 194r, AIChE 1995 Annual Meeting, Miami Beach, 14 November, 1995.

${ }^{20}$ Hesketh, R. P. and C. S. Slater, "Innovative and Economical Bench-scale Process Engineering Experiments," Accepted for Publication in International Journal of Engineering Education December 1999.
}

"Proceedings of the 2002 American Society for Engineering Education Annual Conference \& Exposition Copy- 10 right (C) 2002, American Society for Engineering Education" 
${ }^{21}$ Kantak, M.V., R. H. Aglave and R.P. Hesketh, " Methylamine Oxidation in a Flow Reactor: Mechanism and Modeling," Paper No. 122c, AIChE 1996 Annual Meeting, Chicago, 13 November, 1996.

${ }^{22}$ Kantak, M. V., K S. de Manrique, R. H. Aglave, R. P. Hesketh, "Methylamine Oxidation in Flow Reactors: Mechanism and Modeling." Combustion and Flame, 108235 (1997).

23

Sublette, K. L., R. P. Hesketh, and S. Hasan, "Microbial Oxidation of Hydrogen Sulfide in a Pilot-Scale Bubble Column," Biotech. Progress, 10 611-14 (1994).

"Proceedings of the 2002 American Society for Engineering Education Annual Conference \& Exposition Copy- 11 right (C) 2002, American Society for Engineering Education" 